\title{
Synergistic anti-neoplastic effect of AG1478 in combination with cisplatin or paclitaxel on human endometrial and ovarian cancer cells
}

\author{
NORIYUKI TAKAI, TAMI UEDA, MASAKAZU NISHIDA, KAEI NASU and HISASHI NARAHARA \\ Department of Obstetrics and Gynecology, Oita University Faculty of Medicine, Oita 879-5593, Japan
}

Received December 22, 2009; Accepted March 4, 2010

DOI: $10.3892 / \mathrm{mmr} 00000284$

\begin{abstract}
AG1478, a potent inhibitor of epidermal growth factor receptor (EGFR), facilitates the induction of cell death in combination with a variety of cytotoxic and chemotherapeutic agents in certain human tumor cell lines. The purpose of this study was to elucidate the effect of AG1478 on three endometrial cancer and two ovarian cancer cell lines as compared to normal human endometrial epithelial cells. Cells were treated with various concentrations of AG1478 alone or in combination with the chemotherapeutic drugs cisplatin or paclitaxel, and the effect of AG1478 on cell growth, the cell cycle and apoptosis was investigated. The 3-(4,5-dimethylthiazol-2-yl)-2,5-diphenyltetrazolium bromide assay revealed that all the cancer cell lines were sensitive to the growthinhibitory effect of AG1478. Normal endometrial epithelial cells remained viable after treatment with AG1478 at the same doses as those which induced growth inhibition in the endometrial and ovarian cancer cells. Synergistic anti-neoplastic effects were obtained with a combination of AG1478 and cytostatic drugs. Cell-cycle analysis indicated that exposure to these drugs decreased the proportion of cells in the S-phase and increased the proportion in the sub G0/G1 fractions of the cell cycle. Induction of apoptosis was confirmed by annexin $\mathrm{V}$ staining of externalized phosphatidylserine and by loss of mitochondrial transmembrane potential. These results suggest that AG1478 alone or in combination with chemotherapeutic drugs may be a novel therapeutic option for the treatment of endometrial and ovarian cancer.
\end{abstract}

\section{Introduction}

Endometrial and ovarian cancer are the most common malignant tumors of the female genital tract. Although their

\footnotetext{
Correspondence to: Dr Noriyuki Takai, Department of Obstetrics and Gynecology, Oita University Faculty of Medicine, 1-1 Idaigaoka, Hasama-machi, Yufu-shi, Oita 879-5593, Japan

E-mail: takai@med.oita-u.ac.jp
}

Key words: epidermal growth factor receptor, apoptosis, endometrial cancer, ovarian cancer incidence has increased in recent years (1), the search for agents effective in the treatment of advanced or recurrent endometrial and ovarian cancers has not met with success $(2,3)$. To date, cisplatin, doxorubicin and paclitaxel demonstrate the greatest efficacy $(2,3)$. However, the duration of response remains no longer than $4-18$ months on average $(2,3)$. Therefore, innovative approaches are needed for the treatment of gynecological cancer.

Epidermal growth factor receptor (EGFR) and its downstream signaling pathways are involved in multiple aspects of cancer cell biology, including tumor cell proliferation, the inhibition of apoptosis, invasion, metastasis and angiogenesis (4-7). Moreover, it has been suggested that EGFR overexpression is an indicator of a poor prognosis in lung, breast, ovarian, bladder, esophageal, cervical, and head and neck cancer (8). Accordingly, chemotherapeutic agents targeting EGFR or EGFR-mediated signaling molecules are emerging as novel anticancer drugs.

The quinazoline derivative AG1478 is a small molecule and specific reversible inhibitor of EGFR (Fig. 1) that selectively inhibits the ligand-induced autophosphorylation of EGFR and downstream signal transduction events, including cell proliferation and cell cycle progression (9). Recently, EGFR and its downstream signaling pathways were identified as being associated with cisplatin sensitivity. The cancer cell growth depression effect of AG1478 has been reported in endometrial and ovarian cancer cells $(10,11)$. However, the effect of AG1478 in combination with chemotherapeutic drugs on endometrial and ovarian cancer has not been well described. This motivated us to examine, for the first time, the effect of the EGFR tyrosine kinase inhibitor AG1478 alone and in combination with cisplatin or paclitaxel on endometrial and ovarian cancer cell lines.

\section{Materials and methods}

Cell lines. The Ishikawa human endometrial cancer cell line was kindly provided by Dr Masato Nishida (Tsukuba University, Ibaraki, Japan). The HHUA human endometrial cancer cell line was obtained from Riken (Ibaraki, Japan). The HEC-1B human endometrial cancer and the SK-OV-3 human ovarian cancer cell lines were obtained from the American Type Culture Collection (Manassas, VA, USA). The OMC-3 


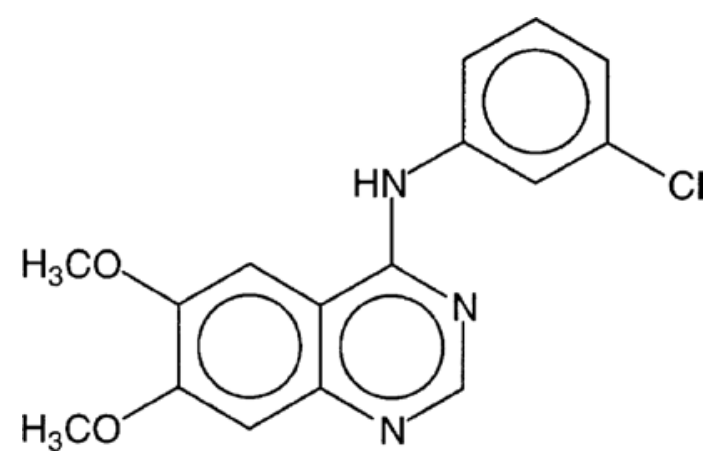

Figure 1. Chemical structure of AG1478.

human ovarian cancer cell line was kindly provided by Dr Masatsugu Ueda (Osaka Medical College, Osaka, Japan). The Ishikawa cells were maintained as monolayers at $37^{\circ} \mathrm{C}$ in $5 \% \mathrm{CO}_{2} /$ air in Dulbecco's modified Eagle's medium (DMEM; Gibco, Rockville, MD, USA) containing 5\% heat-inactivated fetal bovine serum (FBS; Omega, Tarzana, CA, USA). The other four cell lines were maintained as monolayers at $37^{\circ} \mathrm{C}$ in 5\% $\mathrm{CO}_{2}$ /air in RPMI-1640 (Gibco) containing 10\% heatinactivated FBS (Omega).

Normal endometrial epithelial cells. Normal endometrial specimens were obtained from 10 pre-menopausal patients who had undergone hysterectomies for leiomyoma. None of the patients had undergone any hormonal treatments prior to the surgery. All the specimens were diagnosed as being from the late proliferative phase (11-13th day of the menstrual cycle) using a standard histological examination of the endometrial tissues. The study was approved by the institutional review board (IRB) of the Faculty of Medicine, Oita University, and written informed consent was obtained from all patients.

Normal endometrial epithelial cells were separated from stromal cells by digestion of the tissue fragments with collagenase, as described previously (12).

Chemicals. AG1478 was obtained from Calbiochem (San Diego, CA, USA). Cisplatin and paclitaxel were purchased from Sigma (St. Louis, MO, USA).

MTT assay. 3-(4,5-dimethylthiazol-2-yl)-2,5-diphenyltetrazolium bromide (MTT; Sigma) was dissolved in phosphate-buffered saline (PBS; $5 \mathrm{mg} / \mathrm{ml}$ ) and used to measure cellular proliferation. Cells $\left(1 \times 10^{3}\right)$ were incubated with $100 \mu \mathrm{l}$ of culture medium for $72 \mathrm{~h}$ in 96-well plates with the addition of $10 \mu \mathrm{l}$ MTT solution. After $4 \mathrm{~h}$ of incubation, solubilization solution (50 $\mu \mathrm{l}$ of $20 \%$ SDS) was added, and then cells were incubated at $37^{\circ} \mathrm{C}$ for $16 \mathrm{~h}$. In this assay, MTT is cleaved to an orange formazan dye by metabolically active cells. The dye was directly quantified using an enzyme-linked immunosorbent assay reader at $540 \mathrm{~nm}$.

Cell cycle analysis by flow cytometry. The cell cycle was analyzed by flow cytometry after 3 days of culturing as previously described (12). Cells $\left(5 \times 10^{4}\right)$ were exposed to AG1478, cisplatin or paclitaxel in 6-well flat-bottomed plates for $72 \mathrm{~h}$. Analysis was performed immediately after staining using the
CELLFit program (Becton Dickinson, San Jose, CA, USA), whereby the S-phase was calculated using an RFit model.

Measurement of apoptosis (flow-cytometric analysis with the annexin V/propidium iodide assay). Cells were plated and grown overnight to $80 \%$ confluence, then treated with AG1478, cisplatin or paclitaxel. After $72 \mathrm{~h}$, detached cells in medium were collected, and the remaining adherent cells were harvested by trypsinization. The cells $\left(1 \times 10^{5}\right)$ were washed with PBS and resuspended in $250 \mu$ l binding buffer (annexin V-FITC kit; Becton Dickinson) containing $10 \mu \mathrm{l}$ of $20 \mu \mathrm{g} / \mathrm{ml}$ propidium iodide (PI) and $5 \mu \mathrm{l}$ of annexin V-FITC, which binds to phosphatidylserine translocated to the exterior of the cell membrane early in the apoptosis pathway as well as during necrosis. After incubation for $10 \mathrm{~min}$ at room temperature in a light-protected area, the samples were analyzed on a FACSCalibur flow cytometer (Becton Dickinson). FITC and PI emissions were detected in the FL-1 and FL-2 channels, respectively. For each sample, data from 30,000 cells were recorded in list mode on logarithmic scales. Subsequent analysis was performed with CellQuest software (Becton Dickinson).

Mitochondrial transmembrane potential (MTP). Cells were prepared for FACS as described above and stained using the Mitocapture Apoptosis Detection kit (Biovision; Palo Alto, CA, USA) with a fluorescent lipophilic cationic reagent that assesses mitochondrial membrane permeability. Staining was performed according to the manufacturer's recommendation, as previously described (12).

Statistical analysis. Experiments were performed independently at least three times in triplicate for each experimental point. Numerical data are expressed as the means \pm SD. Significance was determined by conducting the paired Student's t-test.

\section{Results}

Effects of AG1478 on the proliferation and viability of normal human endometrial epithelial cells, endometrial cancer cells and ovarian cancer cells in vitro. The antitumor effects of AG1478 on the normal human endometrial epithelial cells (NHEEC), the three endometrial cancer cell lines and the two ovarian cancer cell lines were examined in vitro using an MTT assay with a 3-day exposure to AG1478 (Fig. 2). Compared to the control cells, Ishikawa, HHUA and HEC-1B endometrial cancer cells, and SK-OV-3 and OMC-3 ovarian cancer cells were significantly more sensitive to AG1478 at $10-100 \mu \mathrm{M}$, experiencing a $50 \%$ inhibition $\left(\mathrm{ED}_{50}\right)$ of growth $(\mathrm{p}<0.05)$.

AG1478 chemosensitizes endometrial and ovarian cancer cells to treatment with cisplatin or paclitaxel. We next investigated whether the combination of AG1478 with cytostatic drugs was superior to anti-proliferative treatment with single agents. For combination treatments, individual drugs were used at two different concentrations between their respective $\mathrm{IC}_{10}$ and $\mathrm{IC}_{50}$ values. Each of the cytostatic drugs in combination with AG1478 had a synergistic effect (Ishikawa, Fig. 3; for the other cell lines, data not shown). 

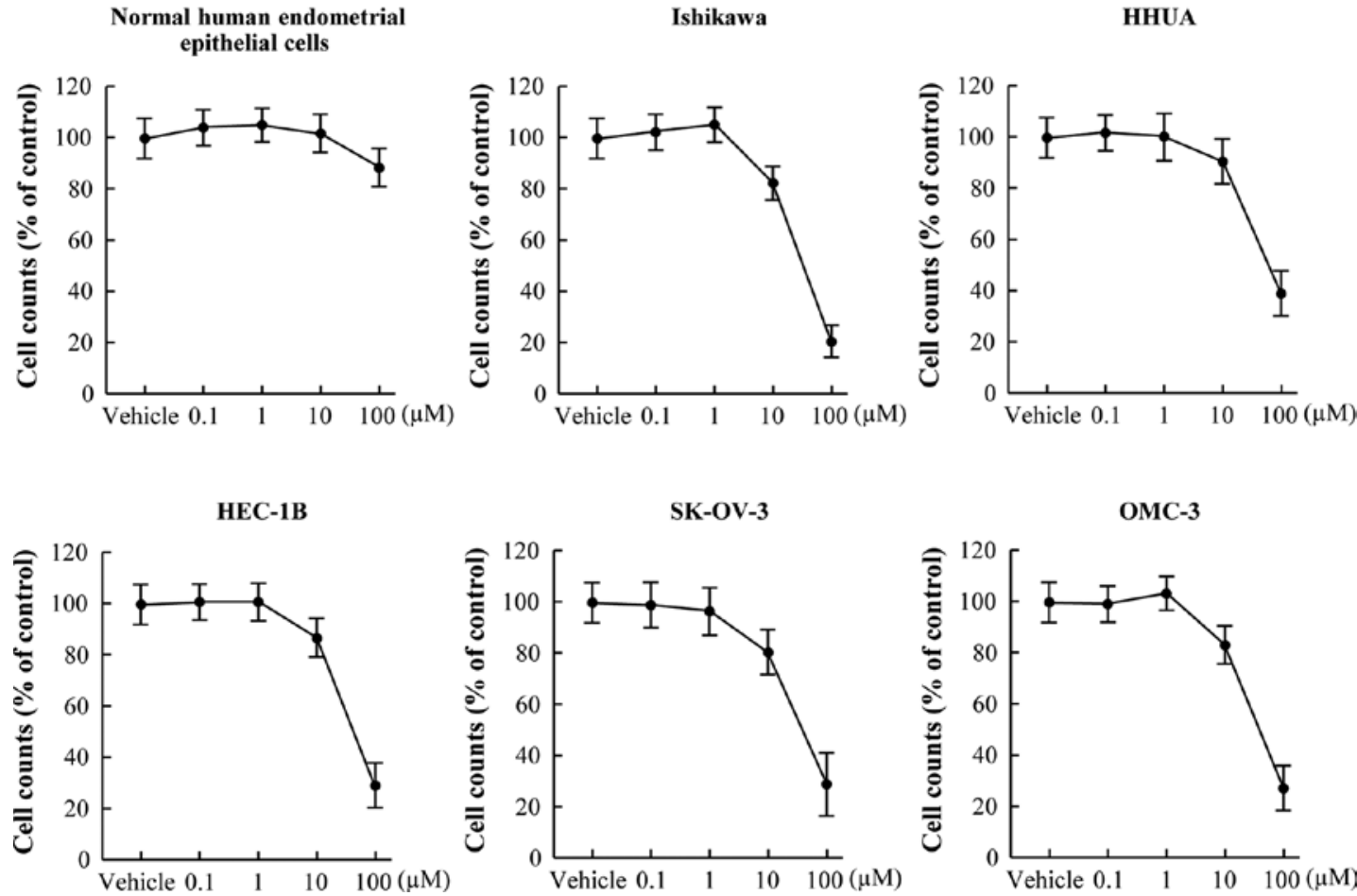

Figure 2. Effect of AG1478 on the growth of endometrial and ovarian cancer cells and normal human endometrial epithelial cells (NHEEC) in vitro. Ishikawa, HHUA and HEC-1B endometrial cancer cells, SK-OV-3 and OMC-3 ovarian cancer cells, and normal human endometrial epithelial cells were treated with AG1478 at various concentrations ( $1 \times 10^{-7}$ to $\left.1 \times 10^{-4} \mathrm{M}\right)$ or with the dilutant (control) for $72 \mathrm{~h}$. Growth (\% of control) was measured using an MTT assay. Results represent the means \pm SD of three independent experiments performed in triplicate.

Cell cycle analysis of endometrial and ovarian cancer cells after exposure to AG1478 in combination with chemotherapeutic drugs. Based on the observed synergism of AG1478 combined with cisplatin or paclitaxel, we investigated whether this combination led to a synergistic induction of apoptosis and/or cell cycle arrest in endometrial and ovarian cancer cells. The combination of AG1478 and cisplatin or paclitaxel led to a marked increase in sub G0/G1 apoptotic cells compared to treatment with either of the agents alone (Table I). This was observed in all the cell lines tested.

Apoptotic changes in endometrial and ovarian cancer cells treated with AG1478 and cytostatic agents. To assess the ability of endometrial and ovarian cancer cells to undergo apoptosis in response to drug exposure and to help distinguish between different types of cell death, cells treated with AG1478 and cytostatic agents were double-stained with annexin V and PI. The results were analyzed using flow cytometry. Annexin V binding combined with PI labeling was performed for the distinction of early apoptotic (annexin $\mathrm{V}^{+} / \mathrm{PI}^{-}$) and necrotic (annexin $\mathrm{V}^{+} / \mathrm{PI}^{+}$) cells. The combination of AG1478 and cisplatin or paclitaxel led to a simultaneous increase in both the annexin $\mathrm{V}^{+} / \mathrm{PI}$ fraction (early apoptotic) and annexin $\mathrm{V}^{+}$ $\mathrm{PI}^{+}$(regarded as necrotic) subpopulations (Table II). This was representative of all the cell lines tested.

Loss of MTP in response to combination treatment with AG1478 and cytostatic agents. Loss of MTP has been shown to occur prior to nuclear condensation and caspase activation, and is linked to cytochrome $c$ release in many, but not all,

\section{Ishikawa}

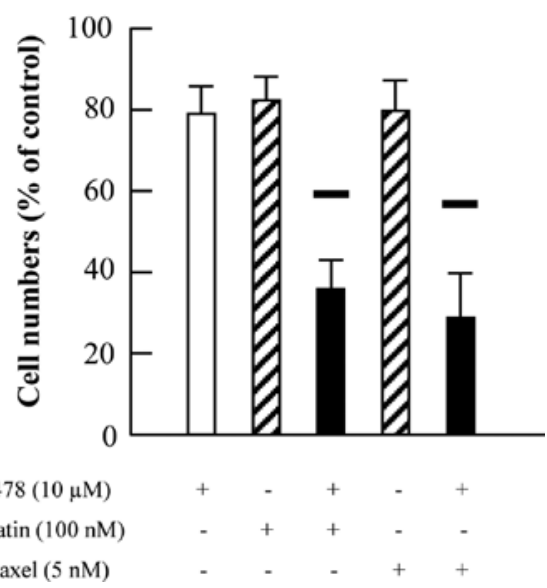

Figure 3. Synergistic growth inhibition of Ishikawa endometrial cancer cells by cytostatic drugs in combination with AG1478. Combination treatment with sub- $\mathrm{IC}_{50}$ concentrations of cytostatic agents (cisplatin or paclitaxel) and AG1478 for $72 \mathrm{~h}$ led to synergistic growth inhibitory effects in the Ishikawa cells. Black bars indicate the values of the calculated additive growth inhibition. Data are presented as the percentage of untreated controls (means \pm SD of at least three independent experiments).

apoptotic cells (13). Using MitoCapture staining and flow cytometry, we analyzed MTP in three endometrial and two ovarian cancer cell lines treated with AG1478 alone or in combination with chemotherapeutic drugs (cisplatin or paclitaxel). Intracellular fluorescence was assayed by FACS after loading cells with an intramitochondrial dye. High 
Table I. Cell cycle changes in endometrial and ovarian cancer cell lines.

\begin{tabular}{|c|c|c|c|c|c|c|}
\hline & Vehicle & $\begin{array}{l}\mathrm{AG} 1478 \\
(10 \mu \mathrm{M})\end{array}$ & $\begin{array}{l}\text { Cisplatin } \\
(100 \mathrm{nM})\end{array}$ & $\begin{array}{l}\text { Paclitaxel } \\
\quad(5 \mathrm{nM})\end{array}$ & $\begin{array}{l}\text { AG1478 }(10 \mu \mathrm{M}) \\
\text { Cisplatin }(100 \mathrm{nM})\end{array}$ & $\begin{array}{l}\text { AG1478 }(10 \mu \mathrm{M}) \\
\text { Paclitaxel }(5 \mathrm{nM})\end{array}$ \\
\hline \multicolumn{7}{|l|}{ Ishikawa } \\
\hline sub G0/G1 & $1 \pm 0$ & $11 \pm 6$ & $22 \pm 10$ & $23 \pm 8$ & $45 \pm 15$ & $55 \pm 17$ \\
\hline $\mathrm{G} 0 / \mathrm{G} 1$ & $49 \pm 9$ & $55 \pm 13$ & $56 \pm 9$ & $59 \pm 12$ & $37 \pm 10$ & $25 \pm 12$ \\
\hline $\mathrm{S}$ & $27 \pm 7$ & $16 \pm 5$ & $12 \pm 5$ & $9 \pm 5$ & $5 \pm 5$ & $7 \pm 5$ \\
\hline $\mathrm{G} 2 / \mathrm{M}$ & $19 \pm 7$ & $16 \pm 10$ & $17 \pm 6$ & $9 \pm 6$ & $9 \pm 6$ & $10 \pm 3$ \\
\hline \multicolumn{7}{|l|}{ HHUA } \\
\hline sub G0/G1 & $1 \pm 0$ & $9 \pm 2$ & $12 \pm 4$ & $13 \pm 4$ & $39 \pm 16$ & $38 \pm 9$ \\
\hline G0/G1 & $41 \pm 10$ & $50 \pm 11$ & $56 \pm 9$ & $53 \pm 7$ & $38 \pm 14$ & $33 \pm 10$ \\
\hline $\mathrm{S}$ & $35 \pm 9$ & $31 \pm 12$ & $13 \pm 5$ & $12 \pm 7$ & $6 \pm 4$ & $11 \pm 3$ \\
\hline $\mathrm{G} 2 / \mathrm{M}$ & $11 \pm 3$ & $8 \pm 2$ & $9 \pm 6$ & $20 \pm 9$ & $17 \pm 8$ & $15 \pm 8$ \\
\hline \multicolumn{7}{|l|}{ HEC-1B } \\
\hline sub G0/G1 & $2 \pm 1$ & $10 \pm 3$ & $12 \pm 8$ & $17 \pm 8$ & $40 \pm 13$ & $42 \pm 17$ \\
\hline $\mathrm{G} 0 / \mathrm{G} 1$ & $46 \pm 8$ & $51 \pm 8$ & $48 \pm 12$ & $50 \pm 9$ & $39 \pm 5$ & $35 \pm 8$ \\
\hline $\mathrm{S}$ & $36 \pm 8$ & $22 \pm 6$ & $17 \pm 7$ & $20 \pm 11$ & $11 \pm 4$ & $9 \pm 5$ \\
\hline $\mathrm{G} 2 / \mathrm{M}$ & $16 \pm 7$ & $16 \pm 8$ & $21 \pm 8$ & $11 \pm 5$ & $8 \pm 4$ & $12 \pm 4$ \\
\hline \multicolumn{7}{|l|}{ SK-OV-3 } \\
\hline sub G0/G1 & $2 \pm 0$ & $12 \pm 7$ & $19 \pm 11$ & $17 \pm 7$ & $55 \pm 11$ & $50 \pm 10$ \\
\hline G0/G1 & $48 \pm 8$ & $59 \pm 13$ & $45 \pm 9$ & $45 \pm 10$ & $29 \pm 7$ & $30 \pm 12$ \\
\hline $\mathrm{S}$ & $35 \pm 9$ & $12 \pm 5$ & $19 \pm 8$ & $26 \pm 9$ & $3 \pm 3$ & $12 \pm 5$ \\
\hline $\mathrm{G} 2 / \mathrm{M}$ & $15 \pm 5$ & $15 \pm 8$ & $15 \pm 9$ & $11 \pm 5$ & $10 \pm 6$ & $7 \pm 7$ \\
\hline \multicolumn{7}{|l|}{ OMC-3 } \\
\hline sub G0/G1 & $3 \pm 1$ & $15 \pm 8$ & $14 \pm 4$ & $19 \pm 6$ & $45 \pm 11$ & $39 \pm 9$ \\
\hline G0/G1 & $40 \pm 6$ & $56 \pm 11$ & $43 \pm 12$ & $50 \pm 10$ & $34 \pm 15$ & $35 \pm 8$ \\
\hline $\mathrm{S}$ & $34 \pm 5$ & $21 \pm 6$ & $15 \pm 2$ & $19 \pm 6$ & $9 \pm 6$ & $12 \pm 3$ \\
\hline $\mathrm{G} 2 / \mathrm{M}$ & $23 \pm 5$ & $7 \pm 3$ & $20 \pm 6$ & $11 \pm 4$ & $11 \pm 4$ & $13 \pm 7$ \\
\hline
\end{tabular}

Endometrial and ovarian cancer cells were plated in triplicate wells and grown for 3 days, and cell cycle distribution was measured. Data are presented as the means $\pm \mathrm{SD}$. Values are expressed as percentages of the control.

fluorescence at $575 \mathrm{~nm}$ (FL2) corresponds to the aggregated form of the dye and is proportional to an intact MTP, whereas loss of MTP leads to a loss of 575 fluorescence and an increase in fluorescence at $525 \mathrm{~nm}$ (FL1; monomeric form of the dye). Treatment of cells with AG1478 and cytostatic agents resulted in the loss of 575 fluorescence and an increase in fluorescence at 525, indicating the loss of MTP (Table II).

\section{Discussion}

In this study, we examined the effect of the EGFR inhibitor AG1478 alone or in combination with cisplatin or paclitaxel on human endometrial and ovarian cancer cell lines. AG1478 had an anti-proliferative effect on endometrial and ovarian cancer cells at micromolar concentrations, while sparing nonmalignant endometrial epithelial cells. In cells treated with combinations of AG1478 and cisplatin or paclitaxel at concentrations less than $\mathrm{IC}_{50}$, a synergistic inhibition of growth was observed (Fig. 3). Moreover, the results indicate that this growth inhibition resulted primarily from the induction of cell cycle arrest and apoptosis.
EGFR is expressed at high levels in a variety of solid tumors. The pleotropic effects of EGFR activation are mediated by the activation of multiple downstream signaling proteins, including extracellular-related kinase (ERK)/ mitogen-activated protein kinase (MAPK), phosphatidylinositiol-3' kinase (PI3K) and STAT3. MAPK and PI3K-AKT signaling are involved in EGFR-dependent growth and survival (14). In addition, these signal transduction molecules have been implicated in tumor-associated motility and invasion $(15,16)$. STAT3 has also been implicated in processes related to tumor cell survival and motility $(17,18)$. As such, EGFR has been identified as an important target for cancer therapy.

Several targeted strategies have been developed to specifically inhibit aberrant EGFR signaling (19). One of these therapeutic strategies involves the development of small molecule tyrosine kinase inhibitors directed against the adenosine triphosphate binding site of the tyrosine kinase domain. The quinazoline derivative AG1478 is the prototype for this class of compounds (20), and is frequently used as a potent and specific EGFR inhibitor in in vitro and cell-based assays 
Table II. Cell death measured by annexin V assay and MTP assay detected by flow cytometry in endometrial and ovarian cancer cells.

\begin{tabular}{|c|c|c|c|c|c|c|}
\hline & Vehicle & $\begin{array}{l}\mathrm{AG} 1478 \\
(10 \mu \mathrm{M})\end{array}$ & $\begin{array}{l}\text { Cisplatin } \\
(100 \mathrm{nM})\end{array}$ & $\begin{array}{l}\text { Paclitaxel } \\
(5 \mathrm{nM})\end{array}$ & $\begin{array}{l}\text { AG1478 }(10 \mu \mathrm{M}) \\
\text { Cisplatin }(100 \mathrm{nM})\end{array}$ & $\begin{array}{l}\text { AG1478 }(10 \mu \mathrm{M}) \\
\text { Paclitaxel }(5 \mathrm{nM})\end{array}$ \\
\hline \multicolumn{7}{|l|}{ Annexin V assay } \\
\hline \multicolumn{7}{|l|}{ Ishikawa } \\
\hline Viable (LL) & $96 \pm 2$ & $77 \pm 12$ & $78 \pm 9$ & $70 \pm 11$ & $26 \pm 7$ & $32 \pm 4$ \\
\hline Apoptosis (LR) & $2 \pm 0$ & $10 \pm 5$ & $10 \pm 4$ & $15 \pm 5$ & $55 \pm 14$ & $43 \pm 18$ \\
\hline Necrosis (UR) & $2 \pm 1$ & $13 \pm 2$ & $12 \pm 7$ & $15 \pm 8$ & $19 \pm 9$ & $25 \pm 8$ \\
\hline \multicolumn{7}{|l|}{ HHUA } \\
\hline Viable (LL) & $94 \pm 3$ & $78 \pm 9$ & $81 \pm 11$ & $78 \pm 9$ & $36 \pm 7$ & $41 \pm 8$ \\
\hline Apoptosis (LR) & $2 \pm 0$ & $10 \pm 5$ & $11 \pm 7$ & $12 \pm 5$ & $37 \pm 11$ & $35 \pm 5$ \\
\hline Necrosis (UR) & $4 \pm 0$ & $12 \pm 3$ & $8 \pm 2$ & $10 \pm 6$ & $27 \pm 8$ & $24 \pm 8$ \\
\hline \multicolumn{7}{|l|}{ HEC-1B } \\
\hline Viable (LL) & $95 \pm 2$ & $86 \pm 6$ & $81 \pm 7$ & $77 \pm 12$ & $44 \pm 15$ & $41 \pm 12$ \\
\hline Apoptosis (LR) & $2 \pm 0$ & $6 \pm 3$ & $10 \pm 2$ & $12 \pm 4$ & $32 \pm 10$ & $37 \pm 11$ \\
\hline Necrosis (UR) & $3 \pm 1$ & $8 \pm 1$ & $9 \pm 2$ & $11 \pm 3$ & $24 \pm 16$ & $22 \pm 5$ \\
\hline \multicolumn{7}{|l|}{ SK-OV-3 } \\
\hline Viable (LL) & $91 \pm 3$ & $77 \pm 11$ & $75 \pm 14$ & $75 \pm 11$ & $39 \pm 19$ & $47 \pm 16$ \\
\hline Apoptosis (LR) & $3 \pm 1$ & $10 \pm 4$ & $12 \pm 7$ & $15 \pm 4$ & $38 \pm 18$ & $39 \pm 14$ \\
\hline Necrosis (UR) & $6 \pm 1$ & $13 \pm 7$ & $13 \pm 5$ & $10 \pm 4$ & $23 \pm 3$ & $14 \pm 7$ \\
\hline \multicolumn{7}{|l|}{ OMC-3 } \\
\hline Viable (LL) & $93 \pm 4$ & $81 \pm 10$ & $80 \pm 11$ & $81 \pm 4$ & $48 \pm 8$ & $38 \pm 7$ \\
\hline Apoptosis (LR) & $4 \pm 1$ & $11 \pm 3$ & $14 \pm 3$ & $10 \pm 2$ & $37 \pm 8$ & $38 \pm 9$ \\
\hline Necrosis (UR) & $3 \pm 0$ & $8 \pm 1$ & $6 \pm 2$ & $9 \pm 1$ & $15 \pm 3$ & $24 \pm 5$ \\
\hline \multicolumn{7}{|l|}{ MTP assay } \\
\hline \multicolumn{7}{|l|}{ Ishikawa } \\
\hline Viable & $96 \pm 2$ & $86 \pm 5$ & $88 \pm 11$ & $80 \pm 7$ & $41 \pm 8$ & $45 \pm 13$ \\
\hline Apoptosis & $4 \pm 1$ & $14 \pm 2$ & $12 \pm 5$ & $20 \pm 3$ & $59 \pm 17$ & $55 \pm 20$ \\
\hline \multicolumn{7}{|l|}{ HHUA } \\
\hline Viable & $95 \pm 3$ & $89 \pm 4$ & $85 \pm 7$ & $85 \pm 8$ & $45 \pm 10$ & $40 \pm 11$ \\
\hline Apoptosis & $5 \pm 1$ & $11 \pm 2$ & $15 \pm 4$ & $15 \pm 4$ & $55 \pm 13$ & $60 \pm 16$ \\
\hline \multicolumn{7}{|l|}{ HEC-1B } \\
\hline Viable & $95 \pm 2$ & $90 \pm 3$ & $83 \pm 11$ & $78 \pm 7$ & $42 \pm 14$ & $43 \pm 11$ \\
\hline Apoptosis & $5 \pm 1$ & $10 \pm 3$ & $17 \pm 4$ & $22 \pm 7$ & $58 \pm 17$ & $57 \pm 13$ \\
\hline \multicolumn{7}{|l|}{ SK-OV-3 } \\
\hline Viable & $91 \pm 3$ & $89 \pm 7$ & $75 \pm 11$ & $72 \pm 5$ & $40 \pm 12$ & $48 \pm 8$ \\
\hline Apoptosis & $9 \pm 1$ & $11 \pm 3$ & $25 \pm 7$ & $28 \pm 2$ & $60 \pm 17$ & $52 \pm 7$ \\
\hline \multicolumn{7}{|l|}{ OMC-3 } \\
\hline Viable & $93 \pm 3$ & $81 \pm 3$ & $80 \pm 7$ & $81 \pm 7$ & $51 \pm 8$ & $39 \pm 8$ \\
\hline Apoptosis & $7 \pm 1$ & $19 \pm 2$ & $20 \pm 2$ & $19 \pm 9$ & $49 \pm 11$ & $61 \pm 19$ \\
\hline
\end{tabular}

Each experiment was repeated three times. Data are presented as the means \pm SD. Values are expressed as percentages of the control.

(21). The cancer cell growth depression effect of AG1478 has been reported pre-clinically in various carcinomas (22-24). Furthermore, AG1478 is in clinical development for brain glioblastoma multiformis in combination with cisplatin (25).

In conclusion, the results presented here suggest that AG1478 alone or in combination with chemotherapeutic drugs may be a new therapeutic option for the treatment of endometrial and ovarian cancers.

\section{Acknowledgements}

This study was supported by a grant (project code FK344 to N.T.) from the Japan Society of Gynecologic Oncology, a Grant-in-Aid (No. 21592139 to N.T.) for Scientific Research from the Ministry of Education, Culture, Sports, Science and Technology, Japan, and a Research Fund at the Discretion of the President, Oita University. 


\section{References}

1. Reinhardt MJ: Gynecologic tumors. Recent Results Cancer Res 170: 141-150, 2008.

2. Obel JC, Friberg G and Fleming GF: Chemotherapy in endometrial cancer. Clin Adv Hematol Oncol 4: 459-468, 2006.

3. Winter WE III, Maxwell GL, Tian C, et al: Tumor residual after surgical cytoreduction in prediction of clinical outcome in stage IV epithelial ovarian cancer: a gynecologic oncology group study. J Clin Oncol 26: 83-89, 2008.

4. Salomon DS, Brandt R, Ciardiello F, et al: Epidermal growth factor-related peptides and their receptors in human malignancies. Crit Rev Oncol Hematol 19: 183-232, 1995.

5. Hiraishi Y, Wada T, Nakatani K, et al: Immunohistochemical expression of EGFR and p-EGFR in oral squamous cell carcinomas. Pathol Oncol Res 12: 87-91, 2006.

6. Huang SM and Harari PM: Epidermal growth factor receptor inhibition in cancer therapy: biology, rationale and preliminary clinical results. Invest New Drugs 17: 259-269, 1999.

7. Prenzel N, Fischer OM, Streit S, et al: The epidermal growth factor receptor family as a central element for cellular signal transduction and diversification. Endocr Relat Cancer 8: 11-31, 2001.

8. Kim SH, Song YC, Kim SH, Jo H and Song YS: Effect of epidermal growth factor receptor inhibitor alone and in combination with cisplatin on growth of vulvar cancer cells. Ann NY Acad Sci 1171: 642-648, 2009.

9. Ben-Bassat H, Rosenbaum-Mitrani S, Hartzstark Z, et al: Tyrphostins that suppress the growth of human papilloma virus 16-immortalized human keratinocytes. J Pharmacol Exp Ther 290: 1442-1457, 1999.

10. Zhao S, Chen X, Lu X, Yu Y and Feng Y: Epidermal growth factor receptor signaling enhanced by long-term medroxyprogesterone acetate treatment in endometrial carcinoma. Gynecol Oncol 105: 45-54, 2007.

11. Arbel R, Rojansky N, Klein BY, Levitzki R, Hartzstark Z, Laufer $\mathrm{N}$ and Ben-Bassat $\mathrm{H}$ : Inhibitors that target protein kinases for the treatment of ovarian carcinoma. Am J Obstet Gynecol 188: 1283-1290, 2003.

12. Takai N, Ueda T, Nishida M, Nasu $K$ and Narahara H: Betahydroxyisovalerylshikonin has a profound anti-growth activity in human endometrial and ovarian cancer cells. Gynecol Oncol 109: 107-114, 2008.
13. Hirsch T, Marchetti P, Susin SA, et al: The apoptosis-necrosis paradox. Apoptogenic proteases activated after mitochondrial permeability transition determine the mode of cell death. Oncogene 15: 1573-1581, 1997.

14. Marmor MD, Skaria KB and Yarden Y: Signal transduction and oncogenesis by ErbB/HER receptors. Int J Rad Oncol Biol Phys 58: 903-913, 2004.

15. Huang C, Jacobson K and Schaller MD: MAP kinases and cell migration. J Cell Sci 117: 4619-4628, 2004.

16. Brader S and Eccles SA: Phosphoinositide 3-kinase signalling pathways in tumor progression, invasion and angiogenesis. Tumori 90: 2-8, 2004.

17. Jing $\mathrm{N}$ and Tweardy DJ: Targeting Stat 3 in cancer therapy. AntiCancer Drugs 16: 601-607, 2005.

18. Gao SP and Bromberg JF: Touched and moved by STAT3. Sci STKE 2006: 30, 2006.

19. Gibbs JB: Anticancer drug targets: growth factors and growth factor signaling. J Clin Invest 105: 9-13, 2000.

20. Levitzki A and Mishani E: Tyrphostins and other tyrosine kinase inhibitors. Ann Rev Biochem 75: 93-109, 2006.

21. Ellis AG, Doherty MM, Walker F, et al: Preclinical analysis of the analinoquinazoline AG1478, a specific small molecule inhibitor of EGF receptor tyrosine kinase. Biochem Pharmacol 71: 1422-1434, 2006.

22. Chen Z, Zhang X, Li M, et al: Simultaneously targeting epidermal growth factor receptor tyrosine kinase and cyclooxygenase-2, an efficient approach to inhibition of squamous cell carcinoma of the head and neck. Clin Cancer Res 10: 5930-5939, 2004.

23. El-Marjou A, Delouvee A, Thiery JP, et al: Involvement of epidermal growth factor receptor in chemically induced mouse bladder tumor progression. Carcinogenesis 21: 2211-2218, 2000.

24. Wakeling AE: Epidermal growth factor receptor tyrosine kinase inhibitors. Curr Opin Pharmacol 2: 382-387, 2002.

25. Nagane M, Narita Y, Mishima K, et al: Human glioblastoma xenografts overexpressing a tumor-specific mutant epidermal growth factor receptor sensitized to cisplatin by the AG1478 tyrosine kinase inhibitor. J Neurosurg 95: 472-479, 2001. 